\title{
ASSESSMENT OF AGE AND GREENNESS OF HERBARIUM SPECIMENS AS PREDICTORS FOR SUCCESSFUL EXTRACTION AND AMPLIFICATION OF DNA
}

\author{
ROY H.J. ERKENS ${ }^{1 *}$, HUGH CROSS ${ }^{2}$, JAN W. MAAS ${ }^{1}$, \\ KIM HOENSELAAR ${ }^{3} \&$ LARS W. CHATROU 4
}

\begin{abstract}
SUMMARY
Age and the greenness of leaves have been frequently used as indicators for selecting herbarium specimens for molecular studies. Although plant DNA extraction and amplification have been common lab procedures for the past 20 years, no studies specifically investigated the success of these indicators. Here the predictive value of age and the greenness for extraction and amplification success is assessed, using a large number of herbarium specimens from different plant groups. The investigation of these indicators is important because herbarium material is a precious commodity, and is often the only remaining floral record of now extinct ecosystems. In cases where little leaf material is available, most researchers still attempt to extract DNA. This study shows that age and greenness of leaves are unreliable indicators of extraction and amplification success, although together they can have limited usefulness. Furthermore, we found that the amount of extracted DNA from herbarium specimens decreases with c. $1 \%$ per year in age of the specimens. Therefore, researchers sometimes should refrain from using old rare specimens because chances of success are unpredictable and precious herbarium material might be wasted. The uncritical use of indicators such as age or leaf colour is therefore not recommendable. Furthermore, botanists should annotate how specimens were collected and dried because this information is essential for successful DNA extraction. Hopefully, similar studies will be reported in order to identify the best approaches to extract DNA from herbarium specimens.
\end{abstract}

Key words: best laboratory practice, herbarium specimen collection and selection, Guatteria, Zehneria, Rauwolf herbarium.

\section{INTRODUCTION}

The use of plant ancient DNA (aDNA) has been steadily growing. The term 'ancient DNA' has been defined as the retrieval of nucleic acids from older organic tissues, including museum collections, archaeological specimens, fossil remains, and many

1) Utrecht University, Faculty of Science, Institute of Environmental Biology, Section Plant Ecology and Biodiversity/Nationaal Herbarium Nederland, Utrecht University branch, Sorbonnelaan 16, 3584 CA Utrecht, The Netherlands.

2) Nationaal Herbarium Nederland, Leiden University branch, Einsteinweg 2, 2333 CC Leiden, The Netherlands.

3) Herbarium, Royal Botanic Gardens, Kew, Richmond, Surrey, TW9 3AB, United Kingdom.

4) Nationaal Herbarium Nederland, Wageningen University branch, Generaal Foulkesweg 37, 6703 BL Wageningen, The Netherlands.

*) Author for correspondence: Tel: 0031-30-2536845; Fax: 0031-30-2518366;

e-mail: R.H.J.Erkens@uu.nl 
other older and unusual sources of DNA (Pääbo et al. 2004). Herbarium specimens are a commonly sought source of DNA for plant studies. However, before the present era of molecular biology herbarium specimens were never collected with the intention to use the material for DNA extraction, and were therefore often not dried under optimal conditions for preservation of the nucleic acids. In addition, some botanists collecting tropical specimens in humid conditions with no drying equipment at hand use methods such as the 'Schweinfurth method' (so called 'wet' or alcohol collecting). Under those conditions this method ensures that mould will not occur and decay of the leaf will not start for at least several months (Bridson \& Forman 1992). However, the use of alcohol (or other mixture of fluids) affects DNA preservation (Doyle \& Dickson 1987; Pyle \& Adams 1989) because the water in the alcohol in specimens treated in this way can continue to degrade DNA. Specimens treated with the 'Schweinfurth method' can be recognised fairly easily because the resulting herbarium material is in most cases brown whereas in fresh-dried material the green colour can be preserved. It is known that the application of methods such as 'Schweinfurth' can substantially lower the molecular weight of DNA recovered (Pyle \& Adams 1989).

DNA molecules in specimens not specifically collected for DNA-based research are more susceptible to degradation by enzymes, bacteria, fungi, and insects that feed on macromolecules (Eglinton et al. 1991). Because of this degradation several studies were conducted to determine which method of DNA extraction is most suitable for herbarium specimens (e.g. Rogers \& Bendich 1985; Savolainen et al. 1995; Drábková et al. 2002; Jankowiak et al. 2005). These studies generally involved a small number of specimens $(<50)$ and investigated which of several extraction methods yielded the highest amount of DNA for these specimens. Although plant DNA extraction and amplification of museum specimens have been common lab procedures for the past 20 years, no reports exist of the extraction and amplification success of a single method used for a large amount of material. Usually, only successful extractions and subsequent amplifications are reported (via for instance a Genbank number); few researchers report on the success rate of their extraction and amplification efforts. Nonetheless, data of the success rate to extract or amplify DNA from certain specimens is very informative for researchers who need to use (often rare) museum collections for molecular research, in order to develop criteria for selecting the best specimens.

When selecting herbarium specimens for extraction of DNA, researchers mostly use age and greenness of the leaves to assess the likelihood of obtaining DNA of sufficient quantity and quality. The greenness of the leaf is thought to indicate the method of drying (Jankowiak et al. 2005). The assumption is that when a specimen is slowly dried (i.e. low heat) it remains green, whereas a quickly dried leaf (i.e. with a lot of heat) turns brown. Jankowiak et al. (2005) recently reported success in extracting DNA from a 100 year-old herbarium specimen of the liverwort Bazzania triloba (Lepidoziaceae). They found in their study of 18 samples that the method of drying (as indicated by the colour of the leaves) was more important for isolation of DNA than the age of the sample. These results agree with earlier studies on the effects of different protocols for DNA extraction such as the extraction from 18 herbarium specimens of Juncaceae (Drábková et al. 2002). However, the colour of leaves is affected by other factors, such as the above mentioned 'wet' collecting. It also varies from family to family and even 
from one species to another due to biological causes. For instance, plants adapted to water stress may possess mechanisms that protect their DNA against natural desiccation and therefore might be more problematic to extract DNA from. In addition, differences in chemical composition of leaves can result in very different dynamics of changes in the leaf colour during the drying process. The advantage is that this can be taxonomically useful. For example, De Wilde \& Duyfjes (2006) used the colour of the leaf after drying as a character to distinguish between closely related species of Cucurbitaceae. However, the disadvantage is that it is difficult to predict the drying dynamics of herbarium material between unrelated lineages.

The comparison of extraction and amplification results of leaves from phylogenetically distinct lineages of angiosperms (from different geographic regions and ages) contributes to our understanding of the usefulness of age and greenness of the leaves as guidelines for selecting herbarium specimens. Here we compare results from three such groups. Because large datasets are time consuming and expensive to generate, we use two datasets that are already available. Herbarium specimens in these two datasets are not older than 240 years and therefore a third available dataset was also included. This dataset contains very few specimens relative to the other two, but are much older (c. 430 years old).

The first dataset is from a recent molecular phylogenetic study (Erkens et al. 2007) of the large Neotropical tree genus Guatteria Ruiz \& Pav. (Annonaceae; Magnoliales, 'magnoliids'). The genus has a wide distributional range, from Mexico to South Brazil, and consists of some 300 species (Erkens et al. In press). Therefore, for many species it was very difficult to obtain freshly collected, silica-dried, leaf material for DNA extraction. Furthermore, the genus has little morphological variation and harbours several species complexes. This made it difficult to assign correct names to some recently collected specimens. In the case of Guatteria several type specimens, undoubtedly belonging to such complexes, were sequenced in order to determine the closest affinity of unidentified specimens.

For comparison, a second recent molecular systematic dataset (Cross et al. in prep.) that contains specimens of several genera in the family Cucurbitaceae (Cucurbitales, 'eurosids I') was considered. The genera under study (primarily Zehneria Endl. but including several others) are found throughout tropical Africa, America, mainland Asia, Indonesia and the Pacific. Because of this broad range and difficulties in obtaining fresh material from throughout the study sites, it was necessary to use herbarium material.

The third dataset consists of eight specimens from research on the historic Rauwolf collection (Cross et al. unpubl.) at the Leiden herbarium (L). These specimens were collected in the Middle East and date to the 1500 s, but are in generally good condition. Specimens representing several plant families (e.g. Poaceae (Poales, 'monocots'), Solanaceae (Solonales, 'eusasterids I')) were sampled.

Although plant DNA extraction protocols have been around for over 20 years, no evaluation of these procedures has been published so far. Many researchers use a 'modified CTAB method' (generally derived from Doyle \& Doyle 1987), but the (successful) modifications are usually not reported and stay confined to the laboratory of that researcher. However, insight into successful methods and procedures, especially for older material, is of importance for many researchers who must select among a very 
few, precious specimens for their studies. Like any museum collection, plant specimens are a valuable resource that should not be squandered. A dialogue among researchers as to the best methods - and reports of the failures as well as the successes - can help avoid the errors of our predecessors. This will prevent more irreplaceable herbarium material ending up at the bottom of a laboratory trash bin.

It is a common assumption that age and greenness of leaves are useful guidelines for selecting herbarium specimens, but assumptions may not be a sound basis for laboratory practice. This study assesses if age and greenness of herbarium specimens are good predictors for successful extraction and amplification of DNA as is generally thought. Hopefully this paper will be the start of a discussion on the use of herbarium specimens for molecular research that is long overdue.

\section{MATERIALS AND METHODS}

\section{Herbarium specimen sampling}

We used 151 herbarium specimens from the Guatteria dataset (voucher information in Appendix 1). The specimens ranged in absolute age from six to 184 years old. From the Zehneria dataset, we evaluated 64 herbarium specimens (voucher information in Appendix 2). The specimens from this dataset ranged in age from 3 to 240 years. For each specimen in these two datasets we qualified the greenness of the leaves by eye as green, green/brown or brown. Finally, we considered eight specimens from the c. 430 year-old Rauwolf herbarium at Leiden. These were selected to represent several plant groups (Appendix 3).

\section{DNA extraction and purification}

All specimens in all studies were extracted according to the protocols described below for each study. The results reported are always first extraction and amplification efforts, unless stated otherwise. After an initial amplification failure subsequent amplifications for the $r b c L$ region were performed in the case of Guatteria to check for the usefulness of internal primers.

The description of methods might seem elaborate in the light of the fact that we only describe 'current practice'. However, although there is a general idea of 'current practice', exact protocols do differ from laboratory to laboratory. Therefore, it is important to specify protocols that were followed.

\section{Guatteria}

We extracted total genomic DNA using a modified cetyl-trimethyl-ammoniumbromide (CTAB) method (Doyle \& Doyle 1987), a method that has performed comparatively well for the extraction of DNA from herbarium specimens (Drábková et al. 2002). $0.05 \mathrm{~g}$ Leaf material was weighed for each sample (large veins were removed) and put into a mortar preheated to $65^{\circ} \mathrm{C}$ with some fine sand and ground to rough powder with a pestle; $650 \mu \mathrm{l}$ CTAB solution was added and ground further; another $650 \mu \mathrm{l}$ CTAB solution was added, mixed, and the whole content of the pestle poured into a $2 \mu 1$ eppendorf tube; $12 \mu 1 \beta$-mercaptoethanol was pipetted into the eppendorf 
tube and mixed again; the eppendorf tube was transferred into a $65^{\circ} \mathrm{C}$ water-bath and left there for 15-20 minutes, mixing thoroughly at least every 5 minutes; thereafter the eppendorf tube was topped off with a $24: 1$ chloroform:isoamylalcohol mixture almost to the rim and placed in a rocking machine for at least 1.5 hours; finally, the tubes were centrifuged at 14,400 rpm for 10 minutes and the top phase was pipetted into a new eppendorf tube.

Purification was done using the Wizard PCR Preps DNA Purification System (Promega Corp.) or the Wizard DNA Clean-up System (Promega Corp.) in combination with a vacuum manifold (Vac-Man Laboratory Vacufold, Promega Corp.) with syringes. Both purification systems performed equally well with respect to DNA yield (data not shown). The DNA was dissolved in $30 \mu \mathrm{l}$ pre-heated elution buffer (Qiaquick PCR Purification Kit, Qiagen). Extraction was considered successful when a band of total DNA or a DNA smear was visible on a $0.6-1 \%$ agarose gel and unsuccessful if not.

\section{Zehneria}

The Zehneria specimens were extracted using the DNeasy plant DNA extraction kit (Qiagen) with modifications as described below. All herbarium material was extracted in the Forensic Laboratory for DNA Research (LUMC, Department of Human Genetics, Leiden University, The Netherlands) where no plant material had been extracted before. Dedicated equipment and reagents were used, and standard aDNA practices were observed (Cooper \& Poinar 2000). For each sample, about one $\mathrm{cm}^{2}$ of leaf material was removed from the herbarium sheet with a sterile forceps and placed in a 1.5 $\mathrm{ml}$ tube. Sterile $3 \mathrm{~mm}$ glass beads and sea sand were placed in the tubes and the leaf material was then ground inside the tube using a Retsch Mill (Retsch Co.). The rest of the extraction proceeded according to the instructions provided by Qiagen (and further specified in the manual), modified for museum material by extending incubation times at least one hour, the addition of $20 \mu \mathrm{l}$ proteinase $\mathrm{k}$, and an additional wash with $100 \%$ ethanol (only if the silica column was still brownish after the first wash). After extraction buffer was added, samples were incubated from six hours to overnight. After incubation and spinning the sample through the Qiashredder column (Qiagen), additional binding buffer was added and this mixture was kept on ice for 20 minutes. For the final elution, 50-75 $\mu \mathrm{l}$ (about half of the prescribed amount) of Buffer AE (or alternatively TE0.1) was added (no differences in elution were detected either using different amounts or different buffers; data not shown), and then incubated for an hour at room temperature, before spinning into a fresh $1.5 \mathrm{ml}$ tube. We measured the quantity of DNA for these extractions with a Nanodrop spectrophotometer (Nanodrop Technologies). A working aliquot of each extraction was made and the bulk was stored in the freezer.

\section{Rauwolf herbarium}

We extracted DNA from the Rauwolf specimens with the DNeasy extraction kit (with modifications as described under Zehneria). Because of their age, the Rauwolf specimens were extracted at the NHN-Leiden aDNA Facility (similar to the previously mentioned Forensic Laboratory for DNA Research with respect to protocols and equipment). Again, we measured the quantity of DNA for these extractions with a Nanodrop spectrophotometer (Nanodrop Technologies). 


\section{DNA amplification}

\section{Guatteria}

We used two plastid markers to test the suitability of the extracted DNA for amplification. Primers 1F/724R (Olmstead et al. 1992) amplified a part of the $r b c L$ gene (c. $700 \mathrm{bp}$ ). We amplified the trnL intron (c. $600 \mathrm{bp}$ ) with the standard c and $\mathrm{d}$ primers (Taberlet et al. 1991). Because these regions are rather large, heavily degraded DNA generally fails to amplify. Therefore, amplification success for these regions can be seen as a measure for how much the DNA is degraded. We checked if the $r b c L$ region could be amplified in smaller fragments (as is to be expected for degraded DNA). Therefore, we applied Annonaceae specific primers 217F and 536R (Pirie et al. 2005) in combination with the previously mentioned $1 \mathrm{~F}$ and $724 \mathrm{R}$ (in the combinations $1 \mathrm{~F}$ - 536R and 217F - 724R).

A standard reaction mix (2.5 $\mu \mathrm{l} 10 \times$ Taq Buffer without $\mathrm{MgCl}_{2}$ (Sigma-Aldrich); $3.5 \mu \mathrm{l} \mathrm{MgCl}_{2}$ (25 mM; Sigma-Aldrich); $1.0 \mu \mathrm{l}$ dNTP's (5 $\mu \mathrm{M}$ each); $0.25 \mu \mathrm{l}$ forward primer $(25 \mu \mathrm{M}) ; 0.25 \mu 1$ reverse primer $(25 \mu \mathrm{M}) ; 0.5 \mu 1$ 'Red' Taq polymerase (SigmaAldrich, $1 \mathrm{U} / \mu \mathrm{l}) ; 1.0 \mu \mathrm{l} \mathrm{BSA}(0.4 \%) ; 15.5 \mu \mathrm{l} \mathrm{H} \mathrm{H}_{2} \mathrm{O} ; 0.5 \mu \mathrm{l}$ DNA; total volume 25.0 $\mu \mathrm{l})$, PCR protocol $\left(35\right.$ cycles; $30 \mathrm{sec} .: 94{ }^{\circ} \mathrm{C}$; $30 \mathrm{sec} .: 53{ }^{\circ} \mathrm{C}$; 1 min.: $72{ }^{\circ} \mathrm{C}$; with an initial 5 min.: $94^{\circ} \mathrm{C}$ and final 10 min.: $72^{\circ} \mathrm{C}$ ) and ABI 9700 Thermal Cycler (Applied Biosystems) were used. Amplicons were purified using a Qiaquick PCR Purification Kit (Qiagen). We scored amplification as failed when no regions could be amplified, partially successful if only one region gave a visible band on a $1.5 \%$ agarose gel and as working when both regions were successfully amplified.

\section{Zehneria}

For the Zehneria study, two plastid markers and a single-copy nuclear gene were amplified (specifications in Cross et al. in prep.). The plastid markers $\operatorname{trn} L-F$ spacer and $\operatorname{trnK}$ spacer produced PCR products of c. $440 \mathrm{bp}$ and c. $180 \mathrm{bp}$, respectively. We amplified a portion of the nuclear gene Glyceraldehyde Phosphate Dehydrogenase (GAPDH), corresponding to exons 7-9 of the Arabidopsis sequence, with several internal primers combinations of which the products range in size from 200-750 bp. The PCR reactions contained $2.5 \mu \mathrm{l}$ of $10 \times$ Taq buffer with $15 \mathrm{mM} \mathrm{MgCl}_{2}, 1 \mu \mathrm{l}$ dNTPs (10 uM), $1.25 \mu \mathrm{l} \mathrm{BSA} \mathrm{(1} \mathrm{mg/ml),} 0.25 \mu \mathrm{l}$ Qiagen Taq polymerase, and $17 \mu \mathrm{l} \mathrm{H}_{2} \mathrm{O}$. The thermal cycler (MJ Research PTC 100) reactions for these reactions were: initial denaturation of $94^{\circ} \mathrm{C}$ for three minutes, followed by 35 cycles of $94^{\circ} \mathrm{C}$ for $25 \mathrm{sec}$., $54^{\circ} \mathrm{C}$ for $60 \mathrm{sec}$, and $72^{\circ} \mathrm{C}$ for $45 \mathrm{sec}$., followed by an extended elongation phase of 5 min. at $72^{\circ} \mathrm{C}$. We purified all PCR products with the Qiagen PCR purification kit (Qiagen) and scored them in the same way as for Guatteria.

\section{Rauwolf herbarium}

For the Rauwolf specimens, we amplified a 120 bp portion of the plastid $r b c L$ gene with primers Z1 af and 19br (Hofreiter et al. 2000). PCR reaction mix, thermal cycling specifications and PCR product purification as described under Zehneria. We scored amplification as failed/(partially) successful as described for Guatteria.

\section{Statistical analyses}

We used SPSS 13.0 for Windows (SPSS Inc. 1989-2004) for two statistical analyses. We applied a logistic regression analysis (with the Backward stepwise (Likelihood Ratio) 
method) to investigate if age and greenness of the leaves are linked to DNA extraction and amplification success. This analysis is suitable in cases where the dependent variable is a dichotomy (e.g. extraction successful yes/no) and the independents are of any type (e.g. age). For each of the analyses the $P$-values from the 'model if term removed'-box are reported and for the combined analyses the omnibus coefficients are presented (omnibus statistics reflect the combined significance of several independent tests of a common hypothesis).

Furthermore, we performed a linear regression analysis to investigate whether age of the leaves was linked to DNA extraction success for the Zehneria dataset (in $\mathrm{ng} / \mu \mathrm{l}$ ) and as the log transformation of the quantity extracted (in $n g / \mu l$ )). In this way, we can estimate how much the quantity of extracted DNA on average increases or decreases per year increase in age (as can be seen from the B-coefficient).

\section{RESULTS}

Out of 151, 105 Guatteria specimens yielded a positive extraction result (69\%; Fig. 1). The oldest specimens of which DNA was extracted and successfully amplified were the 168 years old specimens of Guatteria sordida (both G. sordida var. ovalis and G. sordida var. lanceolata were successfully extracted), the youngest specimens were 7 years old (G. schlechtendaliana and G. pogonopus). We did not succeed in extracting

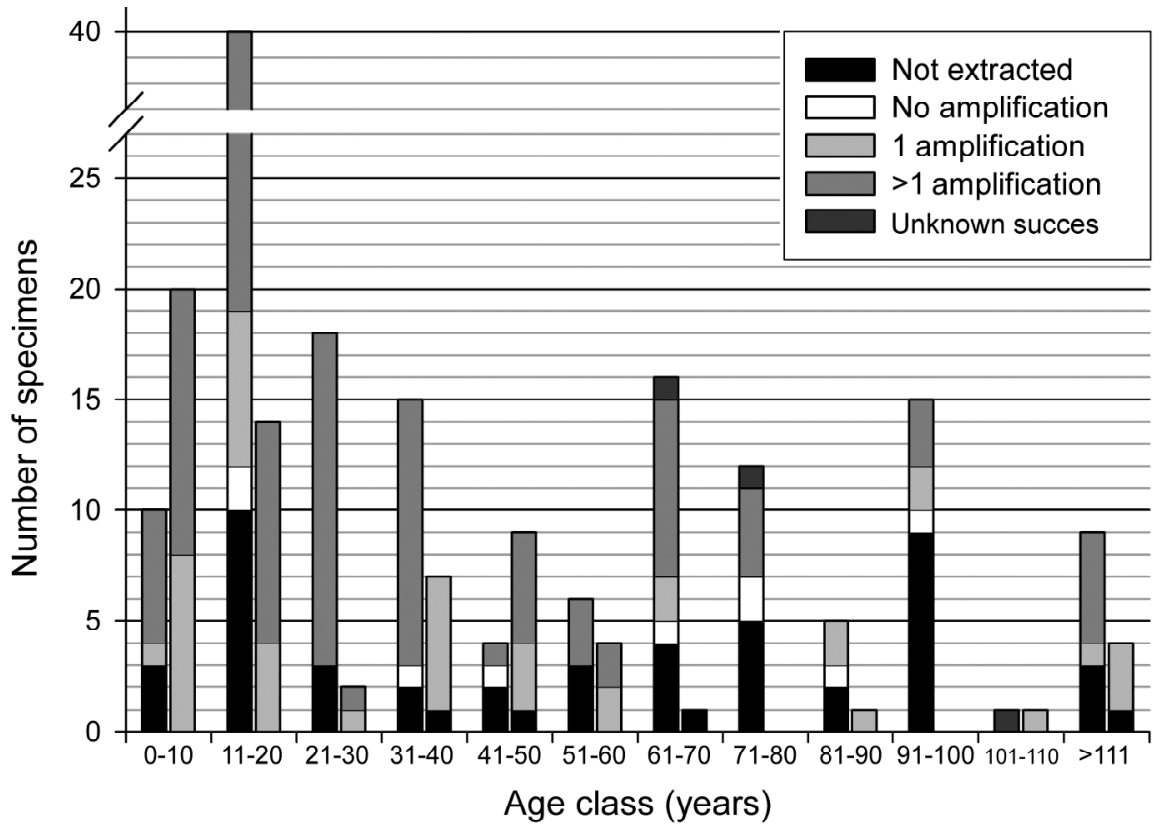

Fig. 1. DNA extraction and amplification success for 2 datasets. Per age class left column represents Guatteria dataset, right column represents Zehneria dataset. Stacked bar height indicates total number of specimens used per dataset in that age class. Number of failed extractions, failed amplifications and successful amplifications (for 1 marker and > 1 marker) is shown. Three Guatteria specimens could be extracted but subsequent amplification success is unknown. Base data in Appendices 1, 2 and 3. 
DNA from the youngest (6 years old) or oldest (184 years old) herbarium specimen. For the Zehneria study, we extracted DNA from 60 out of 63 specimens $(93.5 \%$; Fig. 1). The oldest specimen for which DNA was obtained was a specimen of Cucumis melo of 188 years old. A specimen of Diplocyclos palmatus was the oldest cucurbit available at 240 years, but did not yield any DNA. All specimens from the Rauwolf herbarium produced low amounts of DNA that could be used to amplify the target region.

\section{Guatteria data}

There is no relationship between the age and the greenness of the leaves $(\mathrm{p}=0.672)$, i.e. old leaves do not tend to be browner. Furthermore, a trichotomy in greenness (green, green/brown or brown) did not prove to have any extra explanatory power in the analyses described below (data not shown). Therefore, all analyses were performed with the dichotomous measure green versus non-green (green/brown and brown together).

The relationship between extraction success of a specimen and its age or greenness of the leaf tissue is not significant ( $\mathrm{p}=0.084$ and $\mathrm{p}=0.073$, respectively). If age and greenness are taken together in the analysis as co-variants there is a significant relationship $(p=0.041)$. In other words, DNA is easier extracted from young green leaves than from old brown ones. Taken together with the former results that show no relationship between extraction success and age or greenness separately, we can conclude that it is impossible to predict the success of extraction of DNA from young brown leaves or old green leaves.

When amplification success (dichotomized as 'not/partially working' versus 'both regions amplified' or as 'not working' versus 'one/both regions amplified') is tested for a relationship with age and greenness, age $(\mathrm{p}=0.007$ and $\mathrm{p}=0.008$, respectively) and greenness ( $\mathrm{p}=0.004$ and $\mathrm{p}=0.020$, respectively) both show a significant relationship. Age and greenness analyzed as co-variants show an even stronger relationship $(\mathrm{p}=0.002$ and $\mathrm{p}<0.001)$. This indicates that young green leaves are preferable over old brown leaves in order to obtain an amplicon.

If DNA is successfully extracted from a specimen, amplifications are likely to work (chi-square test; $\mathrm{p}<0.001$ ). Of the 105 successfully extracted specimens of Guatteria 80 (76\%; Fig. 1) amplified for both markers, 15 (14.5\%) amplified only for one of the two markers used and only $10(9.5 \%)$ specimens did not amplify at all. Seven Guatteria accessions failed to amplify for the $r b c L$ region (using standard primers $1 F-724 \mathrm{R}$ ) but were amplified using internal primers (specimens indicated in Appendix 1 by @) indicating that DNA was extracted but too degraded to be amplified using standard primers.

\section{Zehneria data}

There is no relationship between the age and the greenness of the leaves $(\mathrm{p}=0.073)$. As for Guatteria, a trichotomy in greenness did not have any extra explanatory power in the analyses and we performed all analyses with the dichotomous measure green versus non-green. 


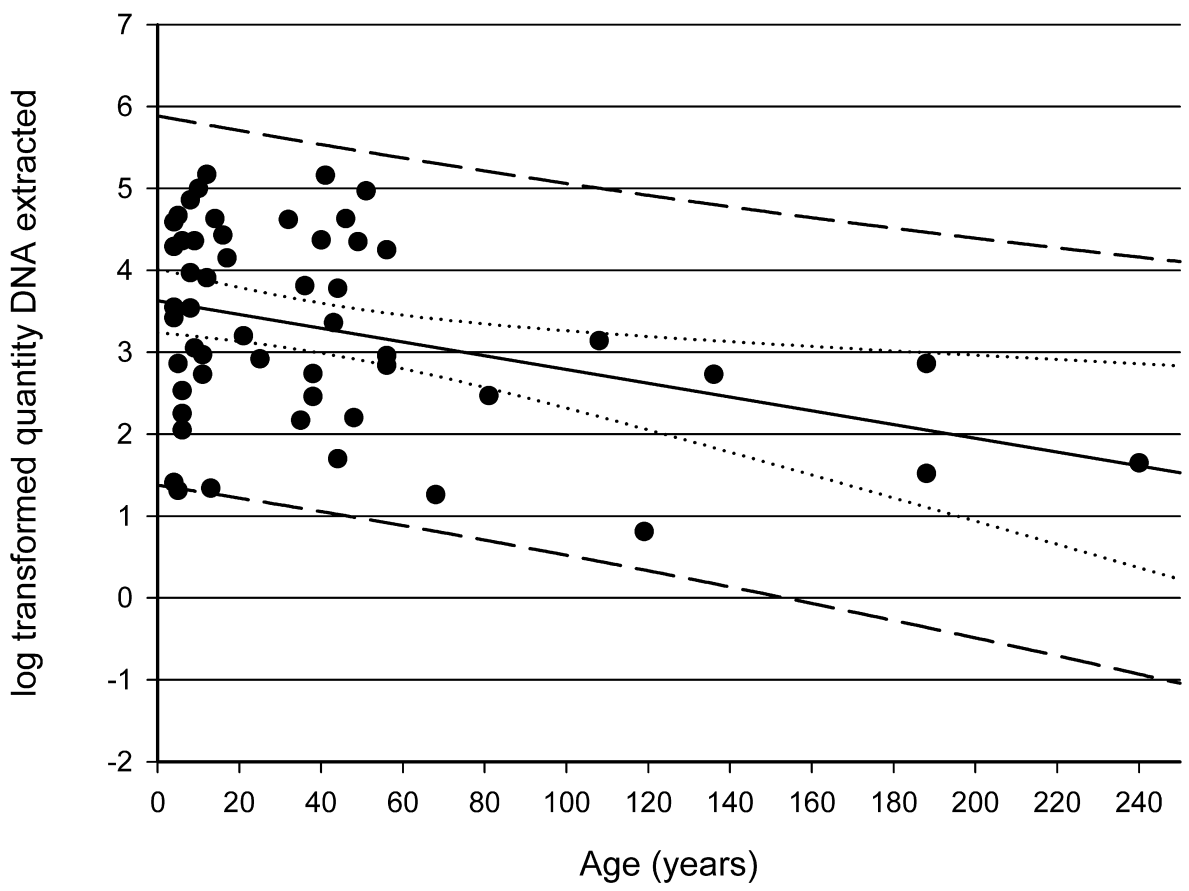

Fig. 2. Log transformed quantity of DNA (ng/ $\mu \mathrm{l})$ extracted as a function of the age of the specimens (years) for the Zehneria dataset. The solid line indicates the regression line, dotted lines indicates the $95 \%$ confidence interval (the range where the regression line values will fall $95 \%$ of the time for repeated measurements) and long dashed lines indicate the $95 \%$ prediction interval (confidence interval for the population; the range where the data values will fall $95 \%$ of the time for repeated measurements).

The relationship between extraction success of a specimen and age is significant $(p=0.018)$ but that between extraction success and the greenness of the leaf tissue is not $(p=0.234)$. If age and greenness are analyzed as co-variants no significant relationship is seen $(\mathrm{p}=0.230)$. This result is in contrast with the result for the Guatteria dataset where combined analysis did show a significant relationship (see above).

There is no linear relationship between the age of the samples and the quantity of DNA extracted (data not shown). However, the relationship between the age of the samples and the log of the quantity of DNA extracted is highly significant $(\mathrm{p}=0.009)$. As shown by the unstandardized ' $\mathrm{B}$ ' coefficient of the regression analysis, for each year a specimen ages the amount of DNA extracted decreases c. 1\% (Fig. 2).

When amplification success (dichotomized as under Guatteria) is tested for a relationship with age and greenness, age ( $\mathrm{p}=0.001$ and $\mathrm{p}=0.018$, respectively) and greenness ( $p=0.004$ and $p=0.230$, respectively) relationships are significant except for the case where amplification was scored as 'not working' versus 'one/both regions amplified'. When analyzed as co-variants age and greenness also show a significant relationship $(\mathrm{p}<0.001$ and $\mathrm{p}=0.024$, respectively). 
Amplifications always worked for at least one of the three markers when DNA was successfully extracted from a specimen (chi-square test; $\mathrm{p}<0.001$ ). Of the 60 successfully extracted specimens 30 (51\%; Fig. 1) amplified for all three markers and 29 (49\%) amplified for two markers used.

\section{Rauwolf data}

The small fragment of $r b c L$ amplified successfully from all the Rauwolf specimens.

\section{DISCUSSION}

Age and the greenness of leaves are thought to be indicators for DNA extraction and amplification success when selecting herbarium specimens for molecular studies. These indicators are easily determined and are important with respect to DNA isolation for several reasons. Age is an important factor because DNA degrades with time (Foran 2006) and specimens in a herbarium are not stored for optimal DNA conservation but for optimal conservation of the visual appearance of the specimen (Bridson \& Forman 1992). The greenness of the leaf tissue is an indicator for the presence of plastids and these are often targeted for the amplification of DNA in phylogenetic studies. However, the link between these two factors and DNA extraction success is not always clear. So far, only some small scale studies have shown that the relationship between age and extraction success might be absent (e.g. Drábková et al. 2002; Jankowiak et al. 2005).

Given that DNA extraction and amplification from herbarium material have been undertaken for over 20 years, statistical estimates for DNA extraction and amplification success might be seen as superfluous. One can also argue that these inferences should be carried out in an experiment designed to include a greater diversity of samples from a wider age range than presented here. However, it is unlikely that such experiments will ever be done. Few laboratories have sufficient budgets and material for such a large-scale, controlled study. In addition, not one but many labs working on different plant groups should engage in such an effort in order to compare results between different taxa. Furthermore, already much unreported data is available from many plant studies. We hope that more comparative studies will be published.

As shown here, for 151 Guatteria herbarium specimens there is no relationship between age and the extraction success of DNA and at first sight this corroborates the earlier qualitative findings of Rogers \& Bendich (1985), Savolainen et al. (1995), Drábková et al. (2002) and Jankowiak et al. (2005). These small scale studies each reported that DNA was successfully extracted from an old specimen and the authors therefore suggested that an apparent correlation between age and DNA extraction or amplification success did not exist. The large Guatteria data set seems to show that this correlation indeed does not exist.

However, there might be a methodological pitfall here. Solely quantifying DNA on agarose gel, as was done in the Guatteria study, might not be sensitive enough to score extraction success because of, for instance, low-copy number template that is below the detection threshold of the gel. In such case, age might erroneously fail to show 
a relationship with extraction success. This idea is supported by the fact that in the Zehneria study for some specimens DNA could be measured with a Nanodrop but no band was visible on a gel (Appendix 2). Furthermore, a relationship between age and extraction success is present in the Zehneria data, even when scored on an agarose gel. Also, the amount of extracted DNA from the specimens in the Zehneria dataset decreased with c. $1 \%$ per year increase in age of the specimens. All this would mean that the suggested absence of a relationship between age and extraction success in the above mentioned studies is not general.

Next to age, greenness is often used as a visual cue for selecting suitable specimens. Here we show that for neither Guatteria nor Zehneria the greenness of leaves predicts the extraction success of a specimen. This probably results from the fact that the age of a specimen is not related to the greenness of the leaves, i.e. older specimens do not tend to be browner. This is especially clear in the Cucurbitaceae dataset where $60 \%$ of the specimens are still green (Appendix 2). If leaves do not turn browner due to aging, the method of drying (suggested by Jankowiak et al. 2005) and the way the specimen was subsequently stored (Bridson \& Forman 1992) are perhaps important factors in determining leaf colour. Both factors are known to determine the quality of the conservation of DNA.

Alternatively, leaves of some species always turn brown upon drying, regardless of the drying method, something that relates to the chemical composition of their leaves. Examples are certain species of Zehneria (De Wilde \& Duyfjes 2006) and Guatteria jefensis (Erkens pers. obs.). Regardless of the fact that the leaves are brown, such specimens still can yield amplifiable DNA as is shown by G. jefensis (Appendix 1).

In contrast to greenness by itself, a combination of age and greenness of leaves (or age by itself in the case of Zehneria) can be used to estimate success in extraction and amplification. Of course, researchers should always use fresh, young leaf material if possible (unless clearly brown from having been treated with the 'Schweinfurth method'). However, the question is what to do with specimens with young-brown leaves, old-green leaves or greenish brown leaves (of any age). If only old-green material is available, most researches still attempt to obtain results simply because this material represents their only source. The Rauwolf dataset indeed shows that small amounts of degraded DNA can be obtained from such specimens. However, in the case of such rare old specimens, researchers should perhaps refrain from using them (or use a nondestructive method, Rohland et al. 2004) because chances of success are unpredictable and precious herbarium material might be wasted if unsuccessful.

The method of drying is a crucial factor in attempts to obtain amplifiable DNA because of the metabolic and cellular processes that damage the DNA when the plant is not dried rapidly enough (Savolainen et al. 1995). Rapid drying is often done with the use of open fire (e.g. burners) and is mostly accompanied by high temperatures (sometimes even burning the specimens). However, the influence of high temperatures on DNA is not straightforward. A study on DNA extraction from charred seeds (Threadgold \& Brown 2003) showed that seeds that were heated to $150{ }^{\circ} \mathrm{C}$ or $200{ }^{\circ} \mathrm{C}$ up to 5 hours still yielded amplifiable DNA, while seeds heated up to $225^{\circ} \mathrm{C}$ or $250^{\circ} \mathrm{C}$ for a short period of time gave no results. To determine in retrospect how hot specimens were when dried 
is of course impossible. However, Blanco et al. (2006) showed that the use of a low temperature air-flow method to dry specimens can help to retain the natural colours of the specimens. Furthermore, these specimens were often more suitable for extraction of DNA. Whether such a method was used by the collector is, like so much else, generally not known to the person attempting to use the specimen for extraction. Because much of what happens to the plant on its way to the herbarium is not recorded and can only be guessed at from the field notes, specimen colour and general information about the locality and standard practice, botanists should annotate how the herbarium specimens were collected and dried and preferably put this information on the label.

Besides the drying, the storage conditions and preservation procedures used in herbaria might also influence the quality of extracted DNA. For instance, herbarium specimens are regularly decontaminated by deep freezing or by the use of a micro-wave oven (Strang 1999). Although freezing does not seem to influence the quality of DNA recovered (Doyle \& Dickson 1987) the use of a micro-wave does (Pyle \& Adams 1989). Furthermore, some older procedures may have resulted in deposits of chemicals on the leaf surface (e.g. copper and mercury remains), the effect of which on the success of DNA extraction and amplification is not known.

Next to numerous biological features of plants (see Introduction; Rogers \& Bendich 1985; Savolainen et al. 1995), the extraction method, PCR program and primers used are crucial in order to obtain good results. The influence of the extraction method is clear from the Rauwolf study in which for two specimens an additional CTAB extraction was done (data not shown but specimens indicated in Appendix 3). The modified CTAB method yielded much more DNA. In the Guatteria study a similar phenomenon was observed (data not shown). In our experience the CTAB method in general yields more DNA than silica-column-based kits, largely because not all DNA will bind to the silica when passing through the column, and much can be lost. However, because silica binds very specifically to DNA, extractions with this method can often result in cleaner DNA. We recommend for older material to extract with a CTAB method, to obtain as much DNA as possible, and if further cleaning is necessary, to take an aliquot of the extractant and purify this through a silica column. Additionally, for more degraded material, further cleaning with silica columns designed for PCR purification, which are designed to bind to smaller fragments of DNA (e.g. Qiagen Qiaquick columns) may yield more DNA. The Guatteria study successfully applied this approach (using the Wizard PCR Preps DNA Purification System (Promega Corp.); see Methods section) and this effect has been documented in other aDNA studies as well (Yang et al. 1998).

With regard to optimizing amplification success, the use of a Nanodrop might be worthwhile (although obtaining a trustworthy estimate of the molecular weight of degraded DNA is highly problematic). Where initial amplifications fail it is important to find out what the nature of the extracted DNA is: low amounts of good quality DNA or large amounts of degraded DNA. Different approaches to address these two problems exist. For the first case: low amounts of generally good quality DNA, several studies have reported success using nested PCR (Grote et al. 2002; Zeng et al. 2005). In this procedure, external primers are used in an initial round of PCR and the products of this reaction are then used as the template for a second round of PCR in which internal 
primers are used. This has been used successfully from as low as a few femtograms of DNA (Zeng et al. 2005).

For the second case, where a higher quantity of heavily degraded DNA is present (and which is more often the case for herbarium specimens), two easily applicable improvements for enhancing amplification success can be applied: the use of internal primers (to amplify a smaller fragment) and/or more specific primers. Both improvements work for good quality DNA but especially for degraded DNA internal primers are a requisite. Seven Guatteria accessions were amplified using Annonaceae specific internal $r b c L$ primers but failed to amplify using the universal primers. The internal primers reduced the length of the fragment from c. $700 \mathrm{bp}$ to only c. $400 \mathrm{bp}$. showing that degraded DNA can still be amplified if smaller fragments are targeted. The same result was found in the Zehneria study, in which a single nuclear gene of c. $700 \mathrm{bp}$ could not be amplified in several older specimens as one amplicon, but using several PCRs with overlapping internal primers of 200-300 bp were successful (Cross et al. in prep.). Furthermore, designing specific primers for the group under study, instead of using the universal primers, also improves chances of obtaining the target amplicon and lessen the risk of contamination. Because the target DNA is present in much smaller quantities than with freshly extracted material, any co-extracted contamination will have a much more negative effect on the efficacy of the PCR.

DNA-repair kits might putatively impact aDNA studies. With such kits it is possible to restore damaged DNA and amplify it with PCR. In the case of a sufficient amount of degraded DNA such a kit might be useful. However, for the Guatteria dataset the GenomePlex Whole Genome Amplification (WGA) Kit (Sigma-Aldrich) was tested but did not improve results. Further reports on the performance of such kits are needed to estimate their value.

Even after 20 years of use of herbarium specimens for DNA extraction, it is difficult to draw up general recommendations in relation to the likelihood of successful DNA extraction and amplification. In Guatteria, age itself is not a strong predictor for success but for Zehneria extractions from older specimens do tend to yield lower amounts of DNA, a result that contradicts the previously suggested absence of such a relationships (Rogers \& Bendich 1985; Savolainen et al. 1995; Drábková et al. 2002; Jankowiak et al. 2005). On the contrary, the Rauwolf herbarium shows that even specimens that are several centuries old can still yield usable DNA. Because of this dependency on the plant group under study, more data is needed on the rate of success of DNA amplification and extraction to be able to formulate more general rules.

Many different responses exist as well to quality differences of DNA in preserved samples. These should be documented further. Data concerning the average and maximum length of fragments obtained from amplifications (for instance for fragments with a frequency above 20\%) are welcomed. These data can serve as a tool for estimating DNA amount and quality, an aspect we were unable to asses and compare well in this study.

Hopefully, the results presented here will encourage others to carry out similar studies in order to identify the best approaches to extract DNA from herbarium specimens. Although the age or greenness of the leaf tissue do not always provide good estimates of success, they do provide a starting point for evaluation. General knowledge of the 
group under study, sound lab practice and experience, as well as gut feeling might still provide the best chance of success at this point.

\section{ACKNOWLEDGEMENTS}

The authors would like to thank the Herbarium of the Royal Botanic Gardens, Kew and the Herbarium of the Swedish Museum of Natural History for granting permission to use their herbarium specimens for DNA extraction, the European Commission's Research Infrastructure Action via the SYNTHESYS Project for funding visits to the Herbarium of the Royal Botanic Gardens, Kew and the herbarium of the Natural History Museum, London, Laszlo Csiba (Molecular Systematics Section, Jodrell laboratory, Royal Botanic Gardens, Kew) for extracting DNA from the Kew herbarium specimens, Barbara Gravendeel (L) for help and support for the Zehneria study, Willem de Wilde and Brigitta Duyfjes (L) for identification of Cucurbitaceae specimens and help with access to these collections, Paul Maas (U) for help with the identification of the Guatteria specimens, Pieter Baas (L) for help with access to Rauwolf specimens, Marcel Eurlings (L) for assistance in the laboratory, and Cas Kruitwagen from the Centre of Biostatistics (Utrecht University) for help with the statistical analyses. Lastly, the authors would like to thank an anonymous reviewer for useful comments on the manuscript.

\section{REFERENCES}

Blanco, M.A., W.M. Whitten, D.S. Penneys, N.H. Williams, K.M. Neubig \& L. Endara. 2006. A simple and safe method for rapid drying of plant specimens using forced-air space heaters. Selbyana 27: 83-87.

Bridson, D. \& L. Forman. 1992. The herbarium handbook. Revised edition. Royal Botanic Gardens, Kew, United Kingdom.

Cooper, A. \& H.N. Poinar. 2000. Ancient DNA: Do it right or not at all. Science 289: 1139.

Dannenfeldt, K.H. 1968. Leonhard Rauwolf, sixteenth-century physician, botanist, and traveler. Harvard University Press, Cambridge, Massachusetts, USA.

De Wilde, W.J.J.O. \& B.E.E. Duyfjes. 2006. Redefinition of Zehneria and four new related genera (Cucurbitaceae), with an enumeration of the Australasian and Pacific species. Blumea 51: 1-88.

Doyle, J.J. \& E.E. Dickson. 1987. Preservation of plant samples for DNA restriction endonuclease analysis. Taxon 36: 715-722.

Doyle, J.J. \& J.L. Doyle. 1987. A rapid DNA isolation procedure for small quantities of fresh leaf tissue. Phyt. Bull. 19: 11-15.

Drábková, L., J. Kirschner \& C. Vlcek. 2002. Comparison of seven DNA extraction and amplification protocols in historical herbarium specimens of Juncaceae. Plant. Mol. Biol. Rep. 20: 161-175.

Eglinton, G., G. A. Logan, R.P. Ambler, J. J. Boon \& W.R.K. Perizonius. 1991. Molecular preservation [and discussion]. Philos. Trans., Ser. B, 333: 315-328.

Erkens, R.H.J., L.W. Chatrou, J. Koek-Noorman, J.W. Maas \& P. J.M. Maas. 2007. Classification of a large and widespread genus of Neotropical trees, Guatteria (Annonaceae) and its three satellite genera Guatteriella, Guatteriopsis and Heteropetalum. Taxon 56: 757-774.

Erkens, R.H.J., L.Y.Th. Westra \& P.J.M. Maas. In press. Increasing diversity in the species-rich genus Guatteria (Annonaceae). Blumea 53/3.

Foran, D.R. 2006. Relative degradation of nuclear and mitochondrial DNA: An experimental approach. J. Forensic Sci. 51: 766-770.

Grote, D., A. Olmos, A. Kofoet, J.J. Tuset, E. Bertolini \& M. Cambra. 2002. Specific and sensitive detection of Phytophthora nicotianae by simple and nested-PCR. Eur. J. Plant. Pathol. 108: 197207.

Hofreiter, M., H. Poinar, W.G. Spaulding, K. Bauer, P.S. Martin, G. Possner \& S. Pääbo. 2000. A molecular analysis of ground sloth diet through the last glaciation. Molec. Ecol. 9: 1975-1984. 
Jankowiak, K., K. Buczkowska \& Z. Szweykowska-Kulinska. 2005. Successful extraction of DNA from 100-year-old herbarium specimens of the liverwort Bazzania trilobata. Taxon 54: 335336.

Olmstead, R.G., H.J. Michaels, K.M. Scott \& J.D. Palmer. 1992. Monophyly of the Asteridae and identification of major lineages inferred from DNA sequences of rbcL. Ann. Missouri Bot. Gard. 79: 249-265.

Pääbo, S., H. Poinar, D. Serre, V. Jaenicke-Despées, J. Hebler, N. Rohland, M. Kuch, J. Krause, L. Vigilant \& M. Hofreiter. 2004. Genetic analyses from ancient DNA. Annual Rev. Genet. 38: 645-679.

Pirie, M.D., L.W. Chatrou, R.H.J. Erkens, J.W. Maas, T. van der Niet, J.B. Mols \& J.E. Richardson. 2005. Phylogeny reconstruction and molecular dating in four Neotropical genera of Annonaceae: the effect of taxon sampling in age estimations. In: F.T. Bakker, L.W. Chatrou, B. Gravendeel \& P.B. Pelser (eds.), Plant species-level systematics: new perspectives on pattern and process: 149-174. Regnum Vegetabile 143. Gantner Verlag, Liechtenstein.

Pyle, M.M. \& R.P. Adams. 1989. In situ preservation of DNA in plants specimens. Taxon 38: $576-581$.

Rogers, S.O. \& A.J. Bendich. 1985. Extraction of DNA from milligram amounts of fresh, herbarium and mummified plant tissues. Pl. Molec. Biol. 5: 69-76.

Rohland, N., H. Siedel \& M. Hofreiter. 2004. Nondestructive DNA extraction method for mitochondrial DNA analyses of museum specimens. BioTechniques 36: 814-821.

Savolainen, V., P. Cuénoud, R. Spichiger, M.D.P. Martinez, M. Crèvecoeur \& J.F. Manen. 1995. The use of herbarium specimens in DNA phylogenetics: evaluation and improvement. Pl. Syst. Evol. 197: 87-98.

Strang, T.J.K. 1999. Sensitivity of seeds in herbarium collections to storage conditions, and implications for thermal insect pest control methods. In: D.A. Metsger \& S.C. Byers (eds.), Managing the modern herbarium. An interdisciplinary approach. Elton-Wolf Publishing, Vancouver BC, Canada.

Taberlet, P., L. Gielly, G. Pautou \& J. Bouvet. 1991. Universal primers for amplification of the three non-coding regions of chloroplast DNA. Pl. Molec. Biol. 17: 1105-1109.

Threadgold, J. \& T.A. Brown. 2003. Degradation of DNA in artificially charred wheat seeds. J. Archeol. Sci. 30: 1067-1076.

Yang, D. Y., B. Eng, J.S. Waye, J.C. Dudar \& S.R. Saunders. 1998. Improved DNA extraction from ancient bones using silica-based spin columns. Am. J. Phys. Anthropol. 105: 539-543.

Zeng, Q., P. Hansson \& X. Wang. 2005. Specific and sensitive detection of the conifer pathogen Gremmeniella abietina by nested PCR. BMC Microbiology 5: 65-74. 


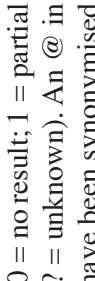

er.

岕芯

क्ष 0 \%

$11 \cdot \frac{0}{0}$

응

हैं

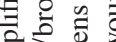

छ छ

它施

व के

N.

$\exists \ddot{\xi}$

0 गं क

II

ठ $=$ లี

范。

II

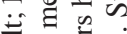

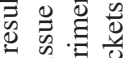

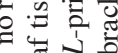

II ฮั

范

के

纪导.

ธี

马 $\frac{1}{3}$

政

बे ठิ

: टै के

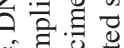

:

क क के

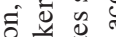

氙 䒕

호을

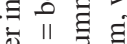

등

웜

$0 \div 80$

б 0

:

范苛

-

츨

름

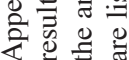

ว.nกรeว รsวนиวว.ID

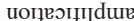

IInjssaoons

บо!ฺวหากхว

uI ssəoons

○

(วฺnฺ๊osq

วธิท

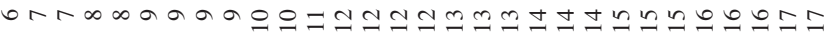

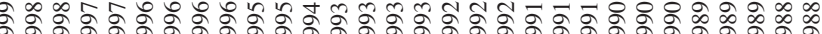

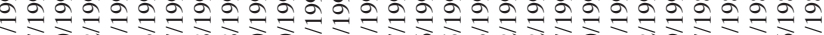

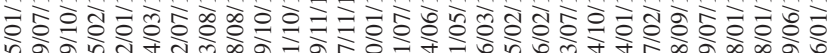

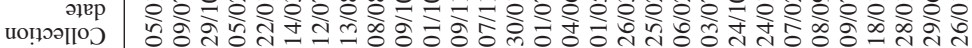

un!..req.ıว

Jәquin

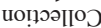

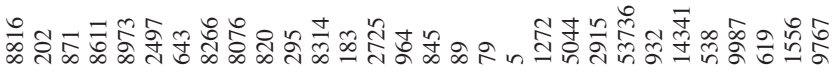

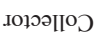

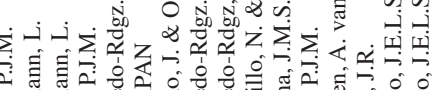

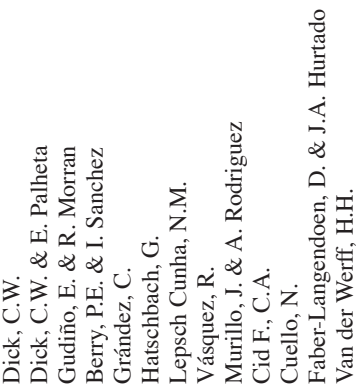

sə๊̣ədS

snuəฺ

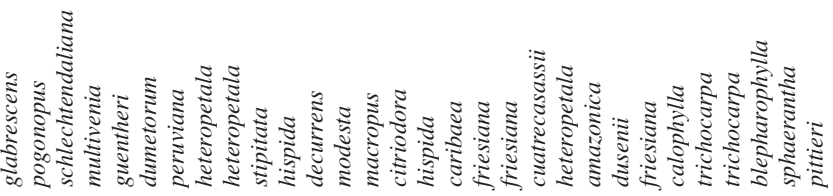

损 VNA 


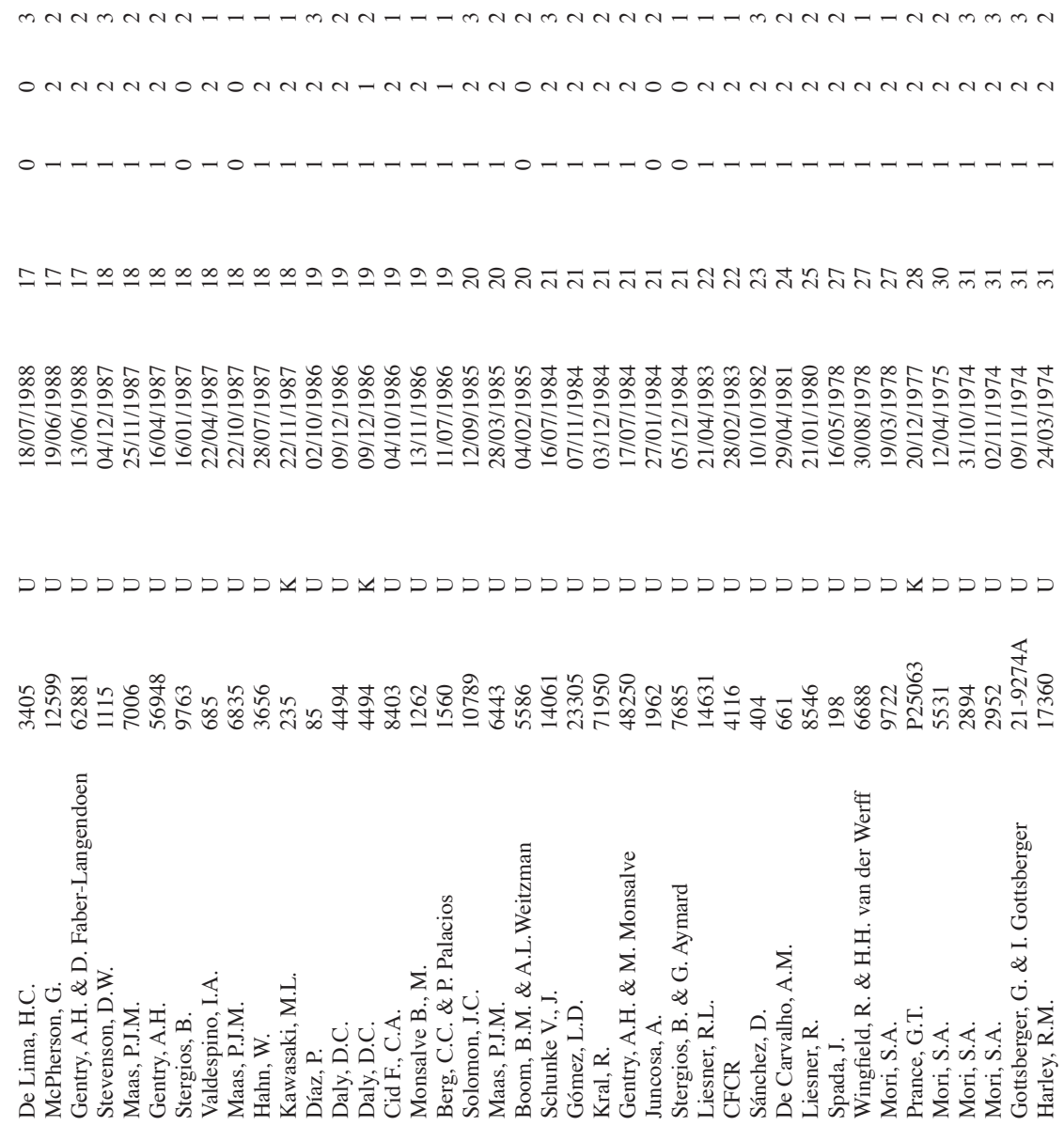

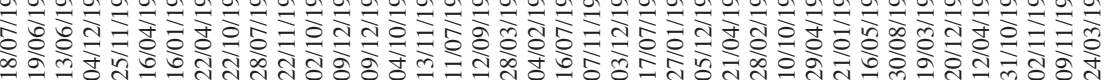

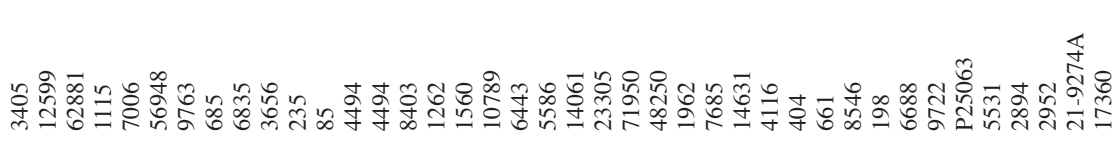

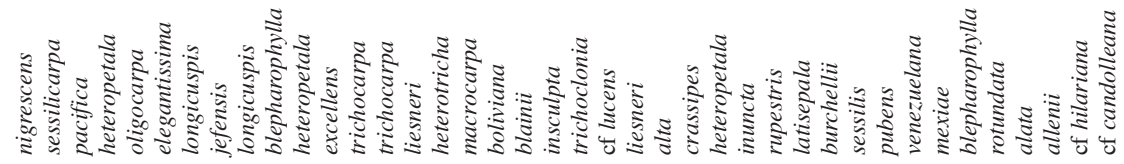




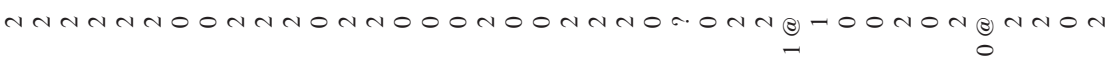

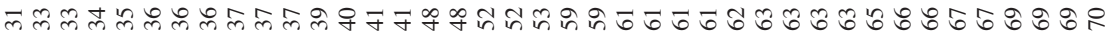

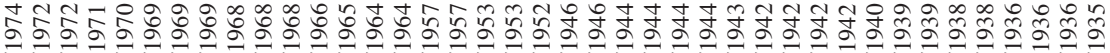
o

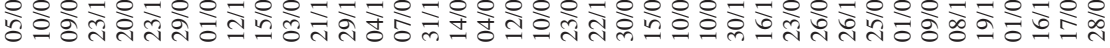

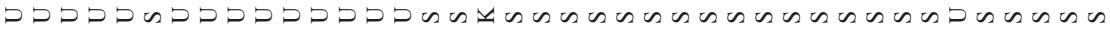

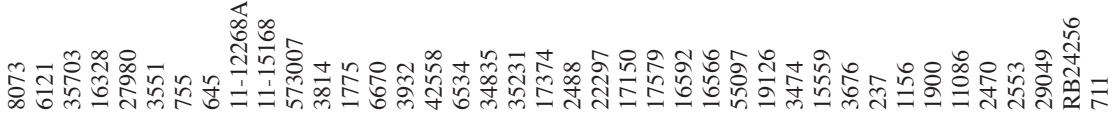

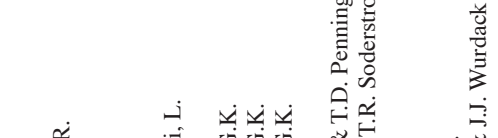

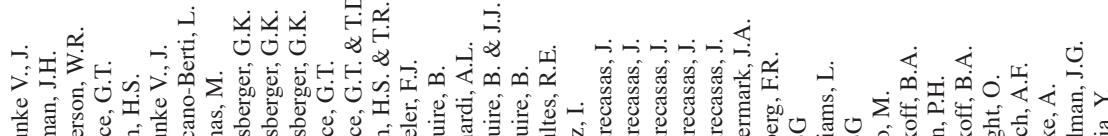

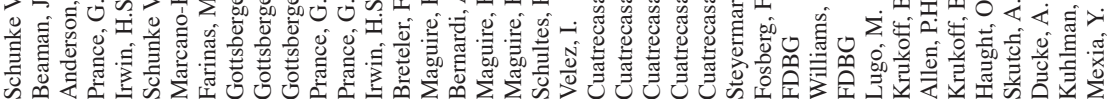

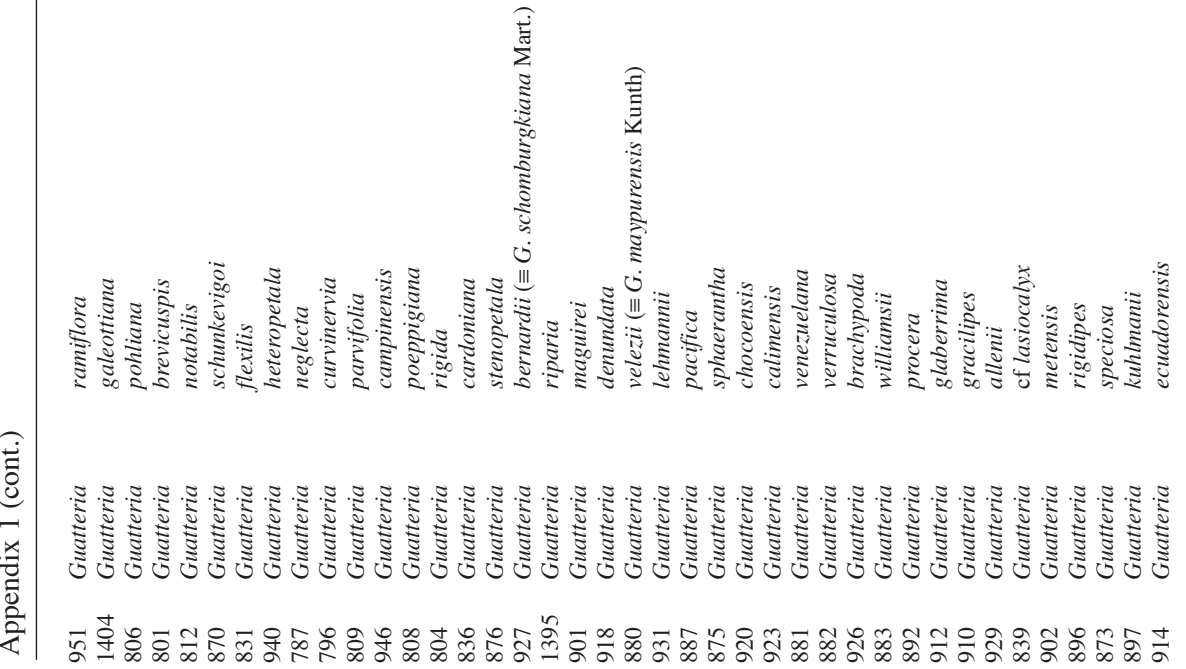




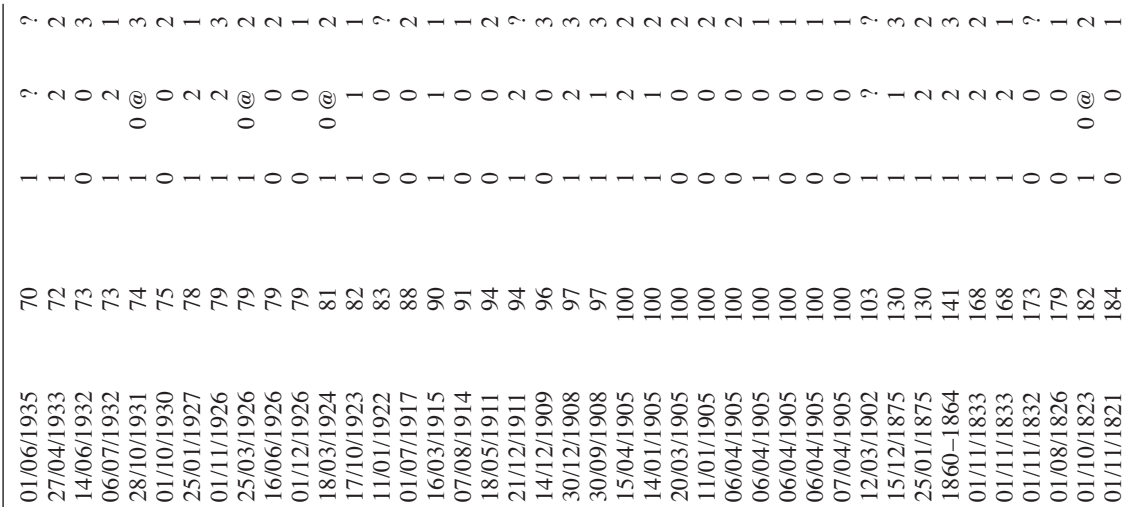

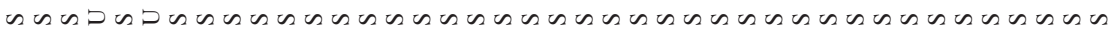

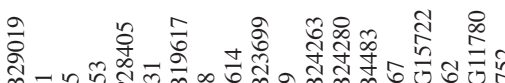

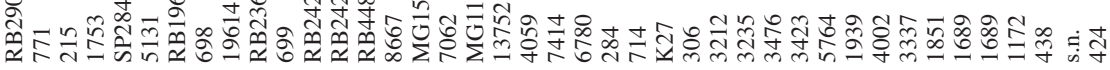

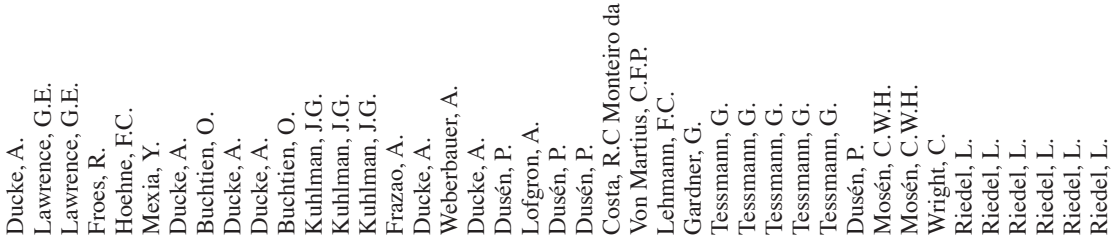

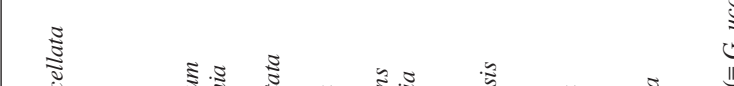

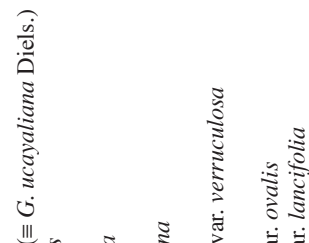

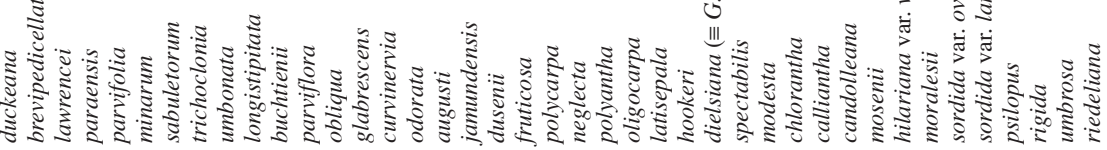




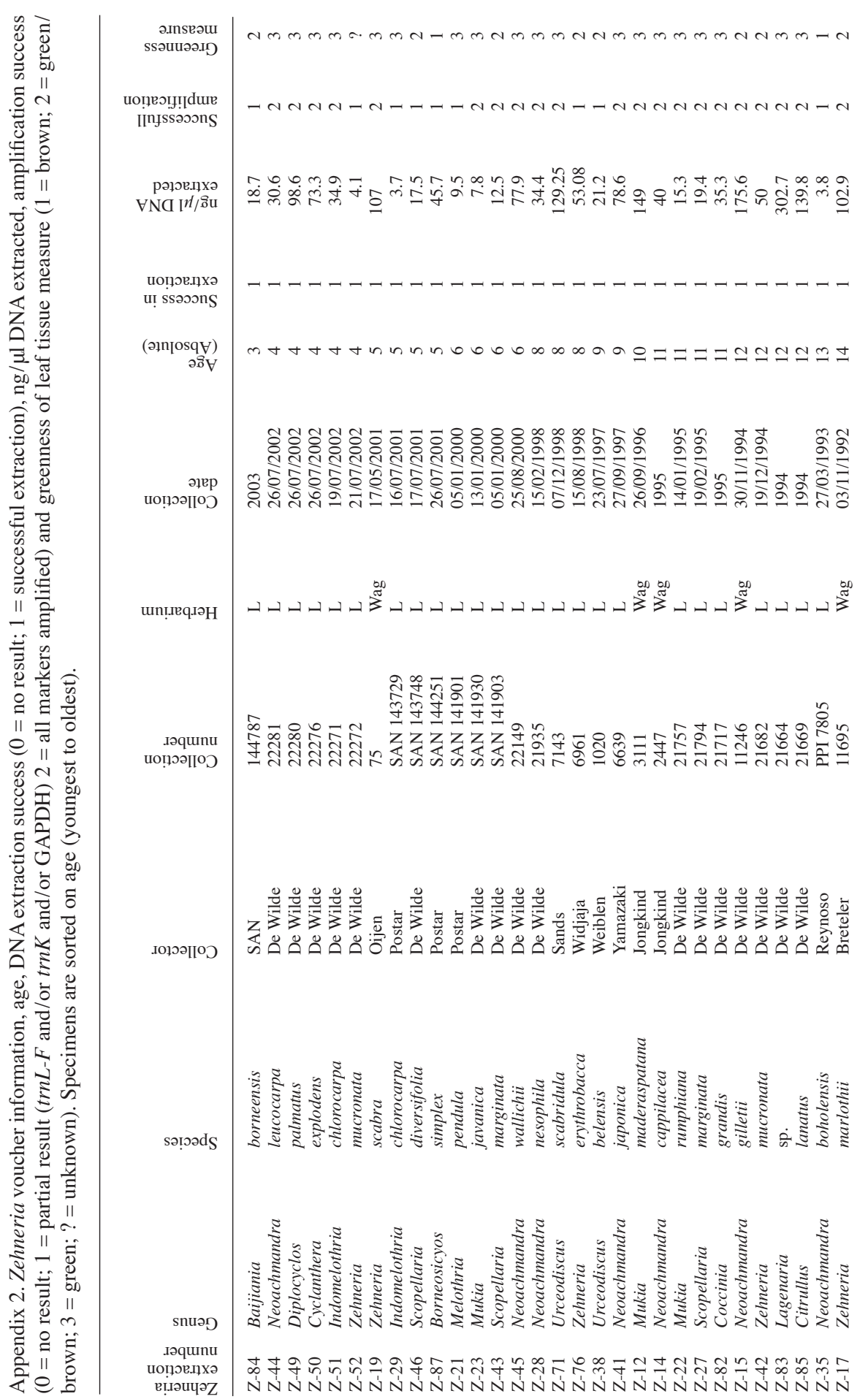




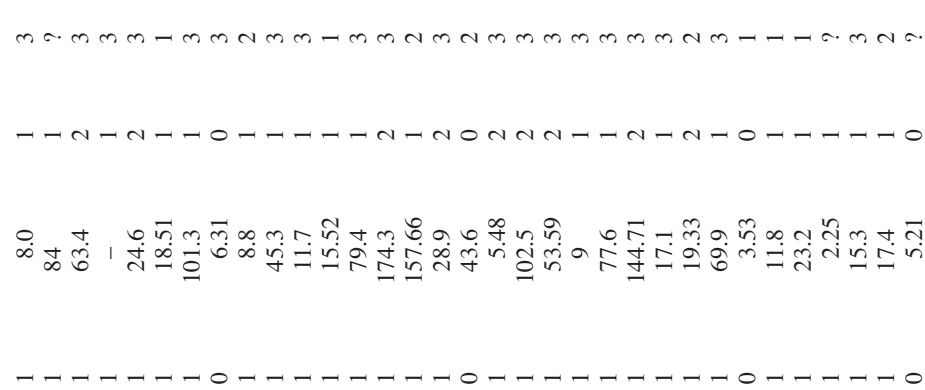

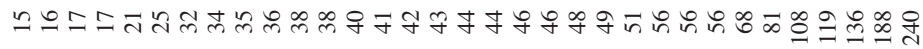

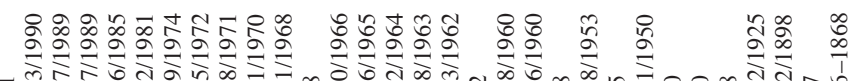

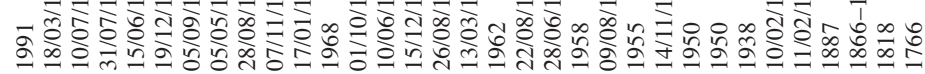

-

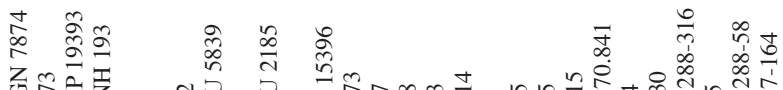

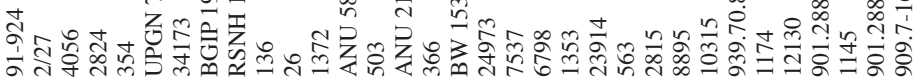

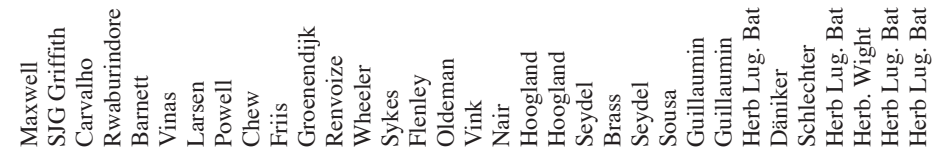

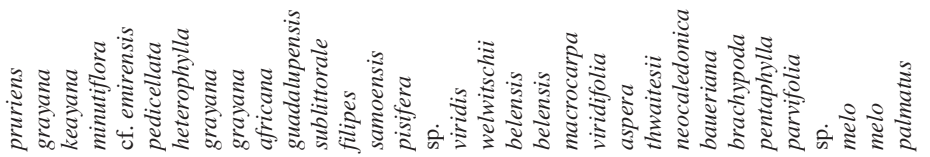


Appendix 3. Information on the extractions from the Rauwolf Herbarium at Leiden Herbarium (L). The German physician Leonhard Rauwolf collected these plants on a trip to the Middle East in the years $1573-1575$. DNA extraction success $(0=$ no result; $1=$ successful extraction), amount of DNA extracted $(\mathrm{ng} / \mu \mathrm{l})$ and amplification success $(0=$ no result; $1=$ successful amplification $)$ are indicated.An@ behind the page number indicates specimens for which an additional extraction was done with a modified CTAB method. Specimens were identified with a combination of Blast search result from GenBank, visual identification of specimen, and record of plants collected by Rauwolf (Dannenfeldt 1968). An asterisk next to the genus name indicates that this was recorded as collected by Rauwolf.

\begin{tabular}{|c|c|c|c|c|c|}
\hline 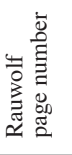 & $\begin{array}{l}\text { 를 } \\
\text { 产 }\end{array}$ & 䇃 & 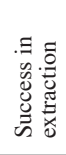 & 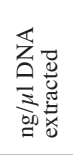 & 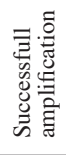 \\
\hline 19 & Poaceae & several & 1 & 4.3 & 1 \\
\hline 34 & Fabaceae & Pisum & 1 & 1.5 & 1 \\
\hline 30 & Fabaceae & Astragalus* & 1 & 12.0 & 1 \\
\hline 30@ & Fabaceae & Astragalus* & 1 & 55.8 & 1 \\
\hline 41 & Hemerocallidaceae & Hemerocallis* & 1 & 38.2 & 1 \\
\hline 64 & Solanaceae & Solanum* & 1 & 2.4 & 1 \\
\hline 64@ & Solanaceae & Solanum* & 1 & 20.5 & 1 \\
\hline 203 & Asteraceae & Carthamus* & 1 & 7.2 & 1 \\
\hline
\end{tabular}

